\title{
Dielectric Properties and Impedance Spectroscopy of RF Sputtered Nanocrystalline (Mg0.95Zn0.05)TiO3 Films for Electronic Applications
}

\section{Pallabi Gogoi}

Indian Institute of Technology Guwahati

Pramila Rani PNVVL

Narasaraopeta Engineering College

K A Emmanuel

Sir CR Reddy Autonomous College

L Robindro Singh

North-Eastern Hill University

Pamu D ( $\nabla$ pamu@iitg.ernet.in )

Indian Institute of Technology Guwahati https://orcid.org/0000-0002-0834-8461

\section{Research Article}

Keywords: Thin films, R-F sputtering, Dielectric response, Nyquist plot

Posted Date: February 10th, 2021

DOI: https://doi.org/10.21203/rs.3.rs-172708/v1

License: (c) (i) This work is licensed under a Creative Commons Attribution 4.0 International License.

Read Full License 


\section{Abstract}

Oxide thin films attracted significant attention because of their favorable responses, especially dielectric and stable electrical properties. In this study, nanocrystalline $\left(\mathrm{Mg}_{0.95} \mathrm{Zn}_{0.05}\right) \mathrm{TiO}_{3}(\mathrm{MZT})$ films are deposited on $\mathrm{Pt} / \mathrm{TiO}_{2} / \mathrm{SiO}_{2} / \mathrm{Si}$ and quartz substrates by radio-frequency (RF) reactive magnetron sputtering. The effect of deposition gas ratio, i.e., the proportion of oxygen and argon $\left(\mathrm{O}_{2} / \mathrm{Ar}\right)$ on broad band and microwave dielectric properties and impedance spectroscopy of MZT films are investigated. The dielectric properties showed a wide range of variation with the different $\mathrm{O}_{2} / \mathrm{Ar}$ ratios. The MZT film deposited in a pure oxygen environment showed the best dielectric properties, and the plasma survived which shows that the target is not fully oxidized. The impedance spectroscopy of the film deposited under a pure oxygen environment exhibited the single semi-circular arc. The Ag/ MZT/Pt thin films capacitors exhibited the best dielectric constant with low loss tangent. The microwave dielectric constant measured at different spot frequencies in the $\mathrm{GHz}$ range displayed inferior dielectric response as compared to their bulk counterparts. An equivalent circuit model to explain the Nyquist plots of MZT films are worked out. The observed electrical and dielectric characteristics of the thin films suggest interesting applications in dielectric mirror and integrated circuits.

\section{Introduction}

The current trend in the global telecommunication industry is drastically favoring miniaturization technologies. Advanced research in dielectric thin-film manufacturing plays a pivotal role in miniaturizing many microwave and integrated optical devices $[1,2]$. Such devices often require high-quality antireflection coatings, the manufacturing of which requires dielectric thin films having superior optical properties [3]. Significant advancements in thin-film capacitor technology can be expected through improvements in high dielectric constant materials, whereby capacitors with increased charge retention (due to low dielectric loss) and high charge density can be easily achieved.

$\mathrm{MgTiO}_{3}$ based thin films find extensive applications compared to other material types due to their excellent dielectric, optical and electrical properties. To improve the utility of $\mathrm{MgTiO}_{3}$ thin films many alterations in the preparation technique, including varying the ionic substitution of $A$ and $B$ sites of $\mathrm{MgTiO}_{3}$ are reported. Still, no reports are available on the electrical and dielectric properties of the films of $\left(\mathrm{Mg}_{0.95} \mathrm{Zn}_{0.05}\right) \mathrm{TiO}_{3}(\mathrm{MZT})$. Various research groups have elaborated their efforts to improve the quality factor of $\mathrm{MgTiO}_{3}$ based ceramics, but reports involving the thin film form of this composition are scarce $[4,7]$. In our previous investigation, we have studied the role of $\mathrm{Zn}$ on the dielectric properties of $\mathrm{MgTiO}_{3}$ ceramics and optimized the best composition as MZT in the bulk form [8]. In the current study, an attempt has been made to prepare MZT thin films using radio frequency (RF) magnetron sputtering. To study the role of nano crystallinity on the structural and electrical properties and compare them with the bulk parameters. The effect of oxygen and argon ratio $\left(\mathrm{O}_{2} / \mathrm{Ar}\right)$ during the deposition of $\mathrm{Zn}$ doped $\mathrm{MgTiO}_{3}$ thin films is studied thoroughly. The correlation between $\mathrm{O}_{2} / \mathrm{Ar}$ ratio induced structural modification and the corresponding changes in microstructural, dielectric, and electrical properties of MZT thin films are 
investigated. Further, impedance spectroscopy is used to determine the contribution of grains and grain boundaries to capacitance, resistance, and conductivity of MZT thin films.

\section{Experimental Details}

The MZT thin films were deposited onto platinized silicon $\left(\mathrm{Pt} / \mathrm{TiO}_{2} / \mathrm{SiO} \mathrm{O}_{2} / \mathrm{Si}\right)$ substrates at room temperature using RF reactive magnetron sputtering. The sputtering chamber was evacuated to a base pressure of $0.001 \mathrm{~Pa}$ while keeping the substrate to the target distance at $4 \mathrm{~cm}$. Pre-sputtering was performed on the target in the Ar atmosphere for $10 \mathrm{~min}$ to clean the target's surface. The processing gas was a mixture of highly pure oxygen (99.999\%) and argon (99.999\%). The RF power (55 W) and the sputtering pressure ( $3 \mathrm{~Pa}$ ) were maintained constant throughout the deposition process. Oxygen and argon $\left(\mathrm{O}_{2} / \mathrm{Ar}\right)$ ratio of $(0: 1),(1: 3),(1: 1),(3: 1)$ and (1:0) were used for film preparation. The $(0: 1) \mathrm{O}_{2} / \mathrm{Ar}$ indicates the presence of pure $\mathrm{Ar}$ in the deposition gas, whereas (1:0) $\mathrm{O}_{2} / \mathrm{Ar}$ indicates the pure $\mathrm{O}_{2}$ environment. The oxygen and argon gas flow is controlled with the help of mass flow controllers. To obtain the equal thickness of all the MZT films (210-230 nm), the rate of depositions was optimized under different $\mathrm{O}_{2} / \mathrm{Ar}$ ratios. Annealing at $600^{\circ} \mathrm{C}$ for $1 \mathrm{~h}$ was necessary for all films to induce crystallinity in the films.

\section{Characterization Details}

The MZT thin films' crystal structure was analyzed by using an X-ray diffractometer (XRD) (M/s Rigaku, TTRAX-III $18 \mathrm{~kW})$. CuKa radiation $(\lambda=1.5406 \AA$ ) in parallel beam configuration was used. The annealed films' surface morphology was studied by atomic force microscope (M/s Bruker, Inova) in the noncontact mode. Split post dielectric resonator (SPDR) connected with Rohde \& Schwarz (ZVA24), Vector network analyzer is used to calculate the microwave dielectric properties of MZT films deposited onto quartz substrates. Metal-insulator-metal (MIM) capacitor structures were fabricated on the films grown under the different $\mathrm{O}_{2} / \mathrm{Ar}$ ratios on a platinized silicon substrate. Silver top electrodes of $0.5 \mathrm{~mm}$ diameter were deposited through a shadow mask for electrical contact. The capacitances, dissipation factors, and other films' electrical parameters were measured in the frequency range from $1 \mathrm{kHz}$ to $1 \mathrm{MHz}$ using an LCR meter (1J43100, M/s Wayne Kerr Electronics Pvt. Ltd.).

\section{Results And Discussions}

\subsection{Crystal structure of the thin films}

The detailed information related to $\mathrm{Zn}$ doped $\mathrm{MgTiO}_{3}$ ceramics with the generic formula $\left[\mathrm{Mg}_{1}\right.$ $\left.\mathrm{Zn}_{\mathrm{x}}\right) \mathrm{TiO}_{3}, x=0.01-0.07$ ] had been reported earlier [8]. The best broadband and microwave dielectric properties were obtained for the sample $x=0.05$ sample, which was sintered at $1275^{\circ} \mathrm{C}$ for $3 \mathrm{~h}$. Therefore, the ceramic with the formula MZT is chosen for the thin films used for this study. 
The MZT films deposited at room temperature are amorphous with a strong glassy background. It is known that oxide films have a natural tendency to grow in an amorphous state as there is no external energy provided to facilitate the crystallinity. Also, the lattice mismatch between the substrate and MZT film is very high. Therefore to induce crystallinity, MZT films were annealed at $600^{\circ} \mathrm{C}$ for $1 \mathrm{~h}$. Figure 1 shows the XRD patterns of the annealed MZT films deposited under different $\mathrm{O}_{2} / \mathrm{Ar}$ ratios on platinized silicon substrates. All the MZT films showed partial crystallinity with an amorphous background even after annealing. A very small and broad reflex of the $\mathrm{MgTiO}_{3}$ phase is observed in the films deposited in pure argon atmosphere $\left((0: 1) \mathrm{O}_{2} / \mathrm{Ar}\right)$.

The broadening of the peak indicates small grain size and more significant influence from inter-grain boundaries. An increase in $\mathrm{O}_{2}$ in $\mathrm{O}_{2} /$ Ar ratio led to an increase in the peaks' amplitude. Some minor secondary peaks $\left(\mathrm{Mg}_{2} \mathrm{TiO}_{4}\right)$ are observed up to the $\mathrm{O}_{2} / \mathrm{Ar}$ ratio (3:1). The appearance of $\left(\mathrm{Mg}_{2} \mathrm{TiO}_{4}\right)$ is impressive as there would be a competition between $\mathrm{MZT}$ and $\mathrm{Mg}_{2} \mathrm{TiO}_{4} \cdot \mathrm{Mg}_{2} \mathrm{TiO}_{4}$ required lower energies than $\mathrm{MZT}$, and $\mathrm{MgTi}_{2} \mathrm{O}_{5}$ is entirely suppressed as it forms naturally during the deposition process. The improvement in the crystallinity with an increase in the $\mathrm{O}_{2}$ ratio may be due to the variations in the ions' momentum during the deposition process. Slow deposition rate in the oxygen environment enhances surface diffusion, which can cause better adhesion, nucleation, and crystallinity [9]. Further, it is worth noting that even in the presence of pure oxygen, we could get an excellent quality thin film indicating that the target is not oxidized entirely even in the presence of reactive gas. The highly intense and sharp reflexes of the $\mathrm{MgTiO}_{3}$ phase are observed in the MZT thin film deposited under (1:0) $\mathrm{O}_{2} / \mathrm{Ar}$ indicates high crystallinity and long-range structural order.

\subsection{Surface morphology of MZT thin films}

The atomic force microscopy (AFM) images of the MZT films deposited under different $\mathrm{O}_{2} / \mathrm{Ar}$ ratios onto platinized silicon substrates are presented in Fig. 2. The influence of the $\mathrm{O}_{2} / \mathrm{Ar}$ ratio on the MZT thin films' morphologies can be observed from the images. It is noted that all the films exhibited a compact microstructure. The variation of $\mathrm{O}_{2} / \mathrm{Ar}$ ratios induced significant changes in the surface morphologies reflected in the respective root mean square (RMS) roughness values. As the $\mathrm{O}_{2}$ content increases in the $\mathrm{O}_{2} / \mathrm{Ar}$ ratio, the average grain sizes of the MZT films are found to be enhanced. In the pure argon atmosphere, the deposition rate is high as a result, the adatoms do not get sufficient time for diffusion and nucleation. This restricts the growth of particles, which leads to a smaller size. Since an increase of $\mathrm{O}_{2}$ concentration in the sputtering gas mixture of $\mathrm{O}_{2} / \mathrm{Ar}$ causes the deposition rate to decrease, the sputtered species' reaction time increases. This facilitates an increase in grain size. The RMS roughness of the deposited films varied between $1.25 \mathrm{~nm}$ to $3.23 \mathrm{~nm}$, as the $\mathrm{O}_{2} / \operatorname{Ar}$ changed from (0:1) to (1:0). The films' RMS roughness enhanced with an increase of $\mathrm{O}_{2}$ in the $\mathrm{O}_{2} / \mathrm{Ar}$ ratio due to better crystallization and larger grain size. Thus, it is substantiated that the improvement in the MZT films' crystallinity is accompanied by an increase in surface roughness and grain size [10]. The observed surface roughness values of the MZT films are lower than the parent $\mathrm{MgTiO}_{3}$ films reported earlier $[6,10,11,12]$. The 
obtained lower RMS roughness of MZT film is suitable for optical devices as they require smoother surfaces.

\subsection{Dielectric properties}

The microwave dielectric properties of MZT thin films are measured using a split post dielectric resonator method at the spot frequencies 5,10 , and $15 \mathrm{GHz}$ and are listed in Table 1 . To measure the dielectric characteristics of MZT films at microwave frequencies the resonance is adopted which gives the better accuracy. It is observed that with an increase in the $\mathrm{O}_{2}$ percentage the dielectric response of the films is enhanced. Further, with an increase in the measurement frequency, the dielectric response is diminished due to the reduction in the contribution from the polarization mechanisms. The improvement of dielectric properties of MZT films with higher $\mathrm{O}_{2}$ in the $\mathrm{O}_{2}$ /Ar ratio can be correlated to reducing oxygen vacancies, development in grain size, and crystallinity of the films [13]. The films deposited under low $\mathrm{O}_{2}$ in the $\mathrm{O}_{2} / \mathrm{Ar}$ ratio exhibited high dielectric losses, which might be due to oxygen vacancies and partial crystallinity. The measured dielectric response is almost in comparison with a bulk counterpart with an inferior loss tangent. The bulk MZT ceramics exhibit lower loss tangents due to the reduction in the grain boundary and strain as they were processed at high sintering temperatures.

Table 1

Microwave dielectric properties of MZT thin films, measured by SPDR technique.

\begin{tabular}{|c|c|c|c|c|c|c|}
\hline & \multicolumn{2}{|l|}{$5 \mathrm{GHz}$} & \multicolumn{2}{|c|}{$10 \mathrm{GHz}$} & \multicolumn{2}{|c|}{$15 \mathrm{GHz}$} \\
\hline $\mathrm{O}_{2} / \mathrm{Ar}$ & $\varepsilon_{r} \tan \delta$ & & $\varepsilon_{r} \tan \delta$ & & $\varepsilon_{\mathrm{r}} \operatorname{tar}$ & \\
\hline$(0: 1)$ & 7.82 & 0.023 & 7.31 & 0.040 & 6.23 & 0.077 \\
\hline$(1: 1)$ & 10.21 & 0.020 & 9.98 & 0.028 & 8.17 & 0.057 \\
\hline$(1: 0)$ & 10.85 & 0.019 & 10.11 & 0.025 & 9.86 & 0.054 \\
\hline
\end{tabular}

Further, the thin-film capacitors are fabricated (Ag/MZT/Pt/TiO $\left.2 / \mathrm{SiO}_{2} / \mathrm{Si}\right)$ under different $\mathrm{O}_{2} / \mathrm{Ar}$ ratios. The dielectric properties of the MZT films were measured over the frequency range of $1 \mathrm{kHz}-1 \mathrm{MHz}$ and are displayed in Fig. 3. It is clear that at lower frequencies, the dielectric constant $\left(\varepsilon_{r}\right)$ is very high due to the contribution from all four types of polarization mechanisms [14]. As the measurement frequency increases, the dipoles cannot align with oscillations of frequency signal which reduces the dielectric constant whereas the loss tangent of MZT films is lower which is the inherent nature of this film. The values are in the range of $\varepsilon_{r} \sim 7.90-12.72$ and $\tan \delta \sim 0.0185-0.0096$ for MZT thin film deposited on platinized silicon substrates.

\subsection{Impedance spectroscopy}

The complex impedance spectroscopy (Nyquist plots) is a beneficial technique used to complete the electrical properties of the polycrystalline ceramics, which include electrode and the grain and grain boundaries contributions. The Nyquist plot is well known for the representation of grain and grain 
boundary response of polycrystalline ceramics [15]. The Nyquist plot usually consists of two adjacent semicircles. The lower frequency semicircle is due to the grain boundary's contribution, and the grain effect is responsible for the semicircle observed in the higher frequency range [16].

Figure 4 shows the Nyquist plots of the MZT films deposited under different $\mathrm{O}_{2} / \mathrm{Ar}$ ratios. All the films exhibited a semi-circular behavior representing the grain and grain boundary response. The experimental impedance data are fitted (shown as "calculated" in Fig. 4) with an equivalent circuit consisting of a resistor $(R)$ and capacitor $(C)$, with the help of ZsimpWin 3.20 software (M/s Echem software, Ann Arbor, Michigan, USA). A series of two sub-circuits composing of resistor and capacitor connected in parallel is well fitted for all the films, which simulate the impedance contribution of grain $(C g, R g)$ and grain boundary $(R g b, C g b)$, respectively, and the obtained fitted values are listed in Table 2 . It is observed that the grain boundary effect is minimized, whereas the grain effect is enhanced with an increase in $\mathrm{O}_{2}$ concentration in the $\mathrm{O}_{2}$ /Ar ratio which lead to higher dielectric constant and lower loss tangent. This might be due to the films' large grain size, as seen in the AFM images (Fig. 2).

Table 2

Capacitance and resistance values of the grains and grain boundaries obtained from the complex impedance plots for MZT films deposited at different $\mathrm{O}_{2} /$ Ar ratios.

\begin{tabular}{|lllll|}
\hline $\mathbf{O}_{2} / \mathrm{Ar}$ & $\mathrm{C}_{\mathrm{g}}(\mathrm{F})$ & $\mathrm{R}_{\mathrm{g}}(\Omega)$ & $\mathrm{C}_{\mathrm{gb}}(\mathrm{F})$ & $\mathrm{R}_{\mathrm{gb}}(\Omega)$ \\
\hline$(0: 1)$ & $6.961 \times 10^{-11}$ & $3.743 \times 10^{4}$ & $7.671 \times 10^{-9}$ & $3.388 \times 10^{4}$ \\
$(1: 3)$ & $5.696 \times 10^{-11}$ & $6.433 \times 10^{5}$ & $4.097 \times 10^{-9}$ & $9.48 \times 10^{4}$ \\
$(1: 1)$ & $1.809 \times 10^{-12}$ & $2.050 \times 10^{4}$ & $5.133 \times 10^{-11}$ & $1.515 \times 10^{5}$ \\
$(3: 1)$ & $5.743 \times 10^{-11}$ & $9.880 \times 10^{5}$ & $4.494 \times 10^{-9}$ & $1.323 \times 10^{5}$ \\
$(1: 0)$ & $6.425 \times 10^{-11}$ & $4.385 \times 10^{5}$ & $1.496 \times 10^{-8}$ & 286 \\
\hline
\end{tabular}

To see the influence of temperature on the impedance, the film capacitor fabricated under $(1: 0) \mathrm{O}_{2} / \mathrm{Ar}$ is exposed to different temperatures, and Nyquist plots are shown in Fig. $5 \mathrm{a} \& 5 \mathrm{~b}$. It is observed that only one semi-circular arc appears up to $433 \mathrm{~K}$. But, from $478 \mathrm{~K}$, a second semi-circular arc started appearing in the low-frequency range. The low-frequency arcs at higher temperatures are due to grain boundary response. All the measured data (msd) are fitted (shown as "cal" in Fig. 5a \& 5b), and obtained values are listed in Table 3. It is observed that the value of $R g$ decreases with the temperature rise, demonstrating the negative temperature coefficient of resistance of these films. This is probably caused by the enhanced movements of defects and charge carriers present in the grain interior and interfacial region of the grains [17] due to higher thermal energy.

Table 3: Capacitance and resistance values of the grains and grain boundaries obtained from the complex impedance plots for MZT films deposited under (1:0) $\mathrm{O}_{2} /$ Ar ratio at different temperatures. 


\begin{tabular}{|cllll|}
\hline Temperature $(\mathrm{K})$ & $\mathrm{C}_{\mathrm{g}}(\mathrm{F})$ & $\mathrm{R}_{\mathrm{g}}(\Omega)$ & $\mathrm{C}_{\mathrm{gb}}(\mathrm{F})$ & $\mathrm{R}_{\mathrm{gb}}(\Omega)$ \\
\hline 298 & $6.425 \times 10^{-11}$ & $4.345 \times 10^{5}$ & $1.496 \times 10^{-8}$ & 286 \\
343 & $6.438 \times 10^{-11}$ & $9.855 \times 10^{6}$ & $6.418 \times 10^{-9}$ & 460 \\
388 & $6.341 \times 10^{-11}$ & $6.658 \times 10^{5}$ & $4.358 \times 10^{-9}$ & 358 \\
433 & $6.372 \times 10^{-11}$ & $5.190 \times 10^{4}$ & $6.077 \times 10^{-8}$ & 376 \\
478 & $7.174 \times 10^{-11}$ & $8.008 \times 10^{4}$ & $1.121 \times 10^{-8}$ & $3.415 \times 10^{4}$ \\
523 & $7.269 \times 10^{-11}$ & $5.333 \times 10^{4}$ & $1.773 \times 10^{-8}$ & $8.032 \times 10^{4}$ \\
568 & $7.388 \times 10^{-11}$ & $4.042 \times 10^{4}$ & $1.453 \times 10^{-8}$ & $2.664 \times 10^{4}$ \\
613 & $7.363 \times 10^{-11}$ & $2.771 \times 10^{4}$ & $1.213 \times 10^{-8}$ & $2.148 \times 10^{4}$ \\
\hline
\end{tabular}

Figure 6 shows the frequency dependence of the real part of impedance $(Z)$ at different temperatures for MZT thin film, deposited under (1:0) $\mathrm{O}_{2} /$ Ar. It is seen that the value of $Z^{\prime}$ decreases with a rise in both temperature and frequency. In the low-frequency region, $Z$ ' shows the sigmoidal variation with frequency. Further increase in frequency, the value of $Z^{\prime}$ decreases and attains a constant value irrespective of temperature for all the films. The reduction in the value of $Z^{\prime}$ with the increase in frequency indicates a slow dynamic relaxation process in the film, which may be attributed to the space charge carriers' mobility. The decrease of $Z^{\prime}$ with a rise in temperature indicates an enhancement in the conduction process [18].

The frequency dependence of the imaginary part of impedance $Z$ "studied at different temperatures, and the results are shown in Fig. 7. A single peak is observed above $100 \mathrm{kHz}$ up to temperature $433 \mathrm{~K}$. From $478 \mathrm{~K}$ onward another small peak appears in the low-frequency region. This peak is correlated to the grain boundary contribution, while the other prominent peak in the high-frequency area is associated with the grain response. This peak moves towards higher frequencies with a temperature rise, and a broadening in the curves is observed with a reduction in peak height. The expansion of the peak with an increase in temperature suggests a temperature-dependent electrical relaxation phenomenon present in the sample. The decline in $Z$ "value with temperature indicates an enhancement in a loss in the film's resistive response [19].

\section{Conclusions}

Nanocrystalline thin films of MZT ceramics are deposited onto platinized silicon and quartz substrates using RF magnetron sputtering. The XRD patterns confirms that phase pure MZT dielectric thin films are deposited under pure oxygen plasma. The dielectric constant and loss tangent values are progressively improved with an increase in $\mathrm{O}_{2}$ in the deposition gas. The maximum values of $\varepsilon_{r} \sim 12.72$ are obtained 
for MZT thin film deposited under (1:0) $\mathrm{O}_{2}$ /Ar due to the higher crystallinity and increased grain size. The impedance behavior of the MZT films is analyzed thoroughly using the Nyquist plot. An equivalent circuit model is well fitted for the films. The observed dielectric characteristics of the thin films suggest interesting applications in dielectric mirror and integrated circuits.

\section{Declarations}

\section{Acknowledgments}

The authors acknowledge the facilities provided by DST-SERB [CRG/2019/00650], India. P. Gogoi acknowledges the Centre for Nanotechnology for providing AFM facility.

\section{References}

[1] Y.H. Choi, and J. Lee, Thin Solid Films 385, 43 (2001).

[2] M.T. Sebastian, Microwave materials and applications, (Wiley,2017).

[3] 0. Auciello, Science and technology of electronic thin films, (Netherlands, Kluwer, 1995).

[4] M.T. Sebastian, R. Ubic, and H. Jantunen Intern. Mater. Reviews 60,392 (2015).

[5] K.P. Surendran, A. Wu, P.M. Vilarinho, and V.M. Ferreira, J. Appl. Phys. 107,114112 (2010).

[6] S.K. Thatikonda, P. Gogoi, A. Perumal, P. Sharma, and D. Pamu, J. Am. Ceram. Soc. 97[4], 1054 (2014).

[7] C.F. Tseng, J. Am. Ceram. Soc. 91, 4125 (2008).

[8] P. Gogoi, L.R. Singh, and D. Pamu, J. Mater. Sci.: Mater. Electronics 28, 11712 (2017).

[9] N. Madaoui, L. Bait, K. Kheyar, and N. Saoula, Adv. Mater. Sci. Eng. 4926543, 1 (2017).

[10] C.L. Huang, and Y.B. Chen, Surf. Coat. Technol. 200, 3319 (2006).

[11] C.L. Huang, S.Y. Wang, Y.B. Chen, B.J. Li, and Y.H. Lin, Current Appl. Phys. 12, 935 (2012).

[12] P. Gogoi, T.S. Kumar, P. Sharma, and D. Pamu, J. Alloys Compounds 619, 527 (2015).

[13] I.T. Kim, Y. Kim, and S.J. Chung, Jpn. J. Appl. Phys. 34, 4096 (1995).

[14] K. Sarkar, and S. Mukherjee, J. Aust. Ceram. Soc. 52[2], 32 (2016).

[15] S. Fillipovic, V.P. Pavlovic, N. Obradovic, V. Paunovic, K. Maca, and V.B. Pavlovic, J. Alloys compounds 701,107 (2017).

[16] K. Funke, Prog. Solid State Chem. 22, 111 (1993). 
[17] M.S. Samuel, J. Koshy, A. Chandran, and K.C. George, Current. Appl. Phys. 11, 1094 (2011).

[18] Z. Imran, M.A. Rafiq, M. Ahmad, K. Rasool, S.S. Batool, and M.M. Hasan, AIP Advnces. 3,032146 (2013).

[19] R. Tang, C. Jiang, W. Qian, J. Jian, X. Zhang, H. Wang, and H. Yang, Scientific Rep. 5, 13645 (2015).

\section{Figures}

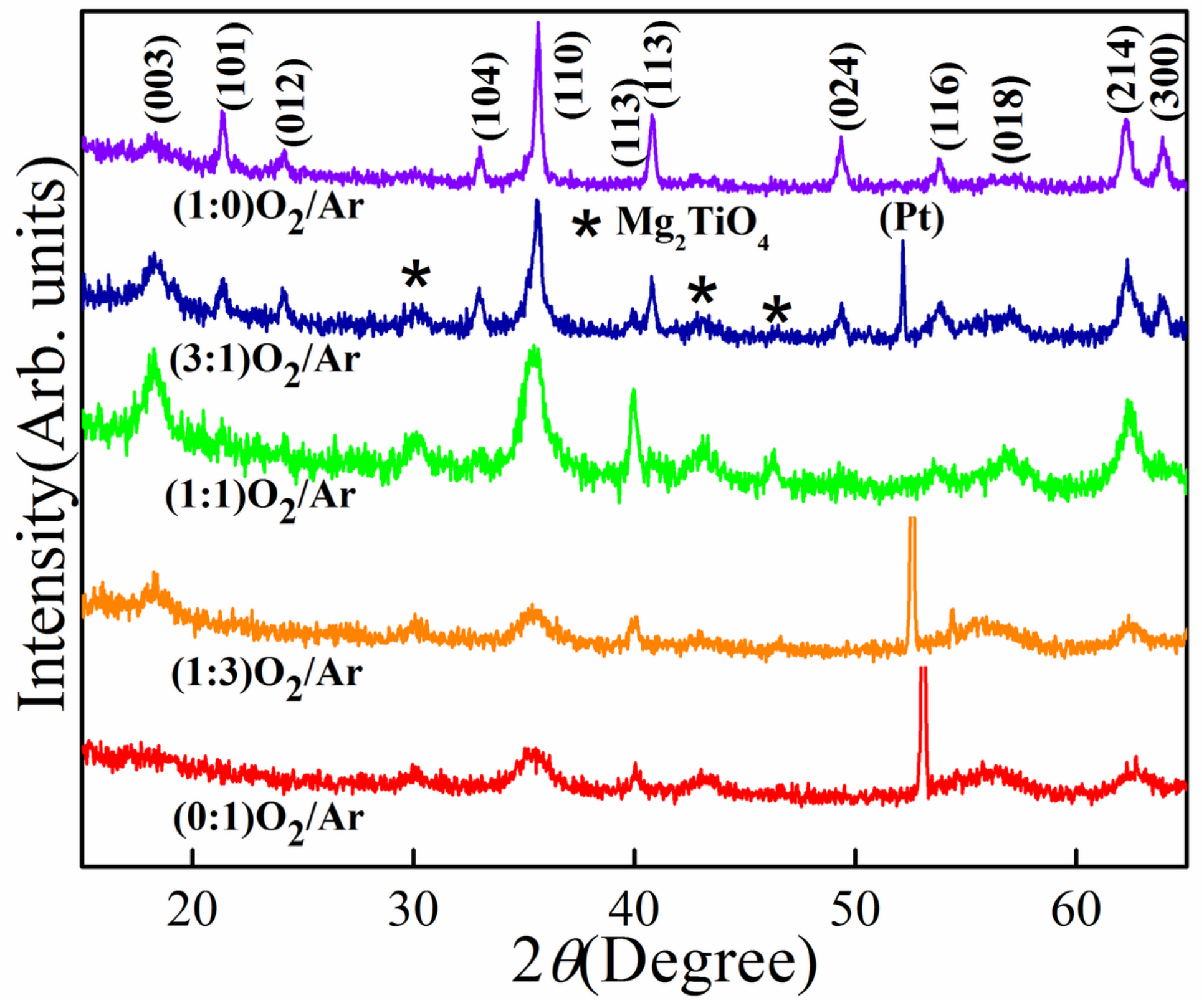

Figure 1

XRD patterns of the annealed MZT films deposited on Platinized silicon substrates at different O2/Ar ratios. 

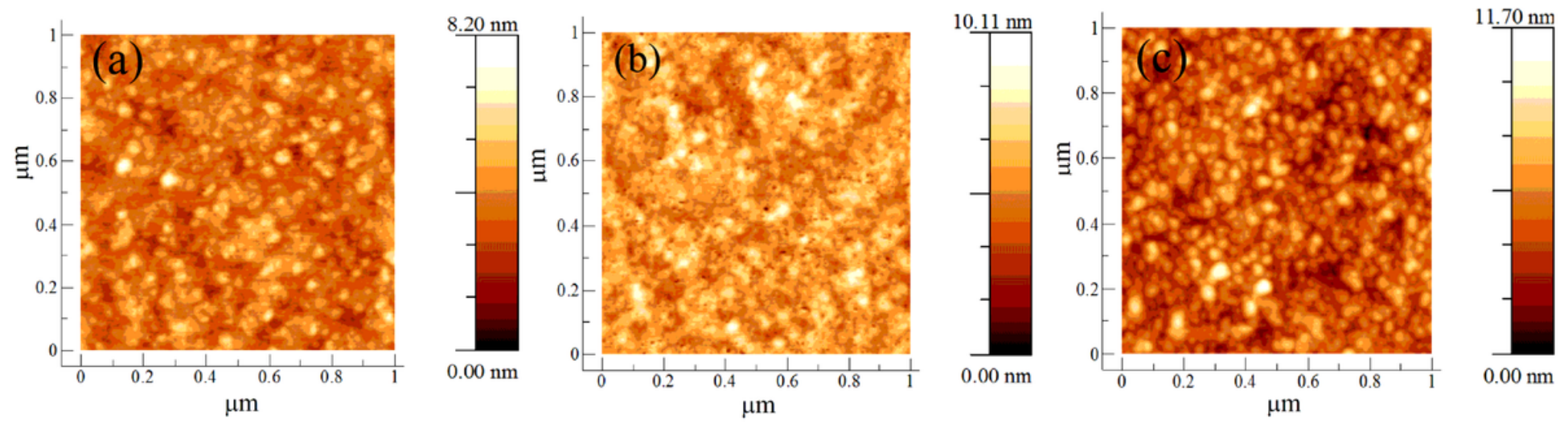

Figure 2

AFM images of the annealed MZT thin films deposited on platinized silicon substrates under (a) $(0: 1)$ O2/Ar, (b) (1:1) 02/Ar and (c) (1:0) 02/Ar.
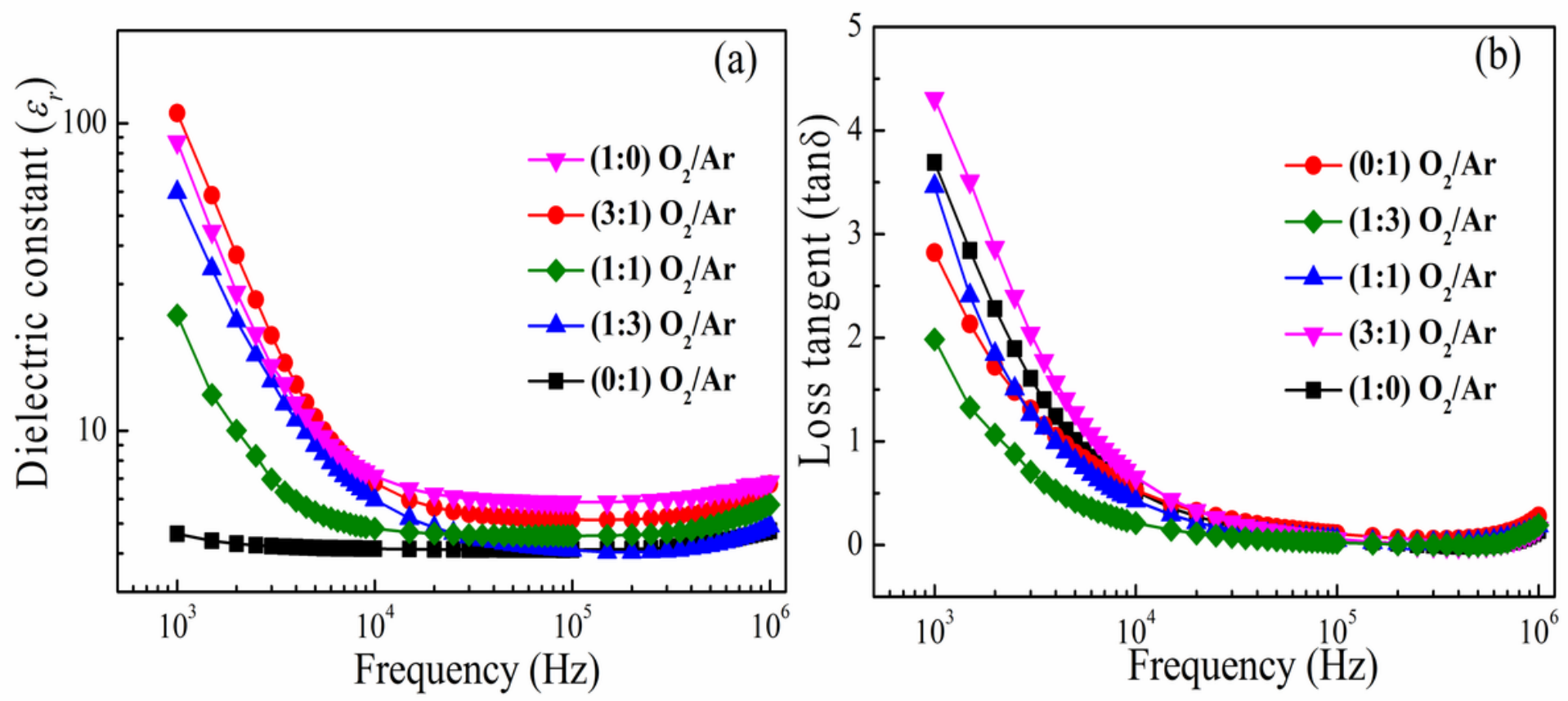

Figure 3

Variation of (a) dielectric constant and (b) loss tangent as a function of the frequency of MZT films deposited under different 02/Ar ratios. 

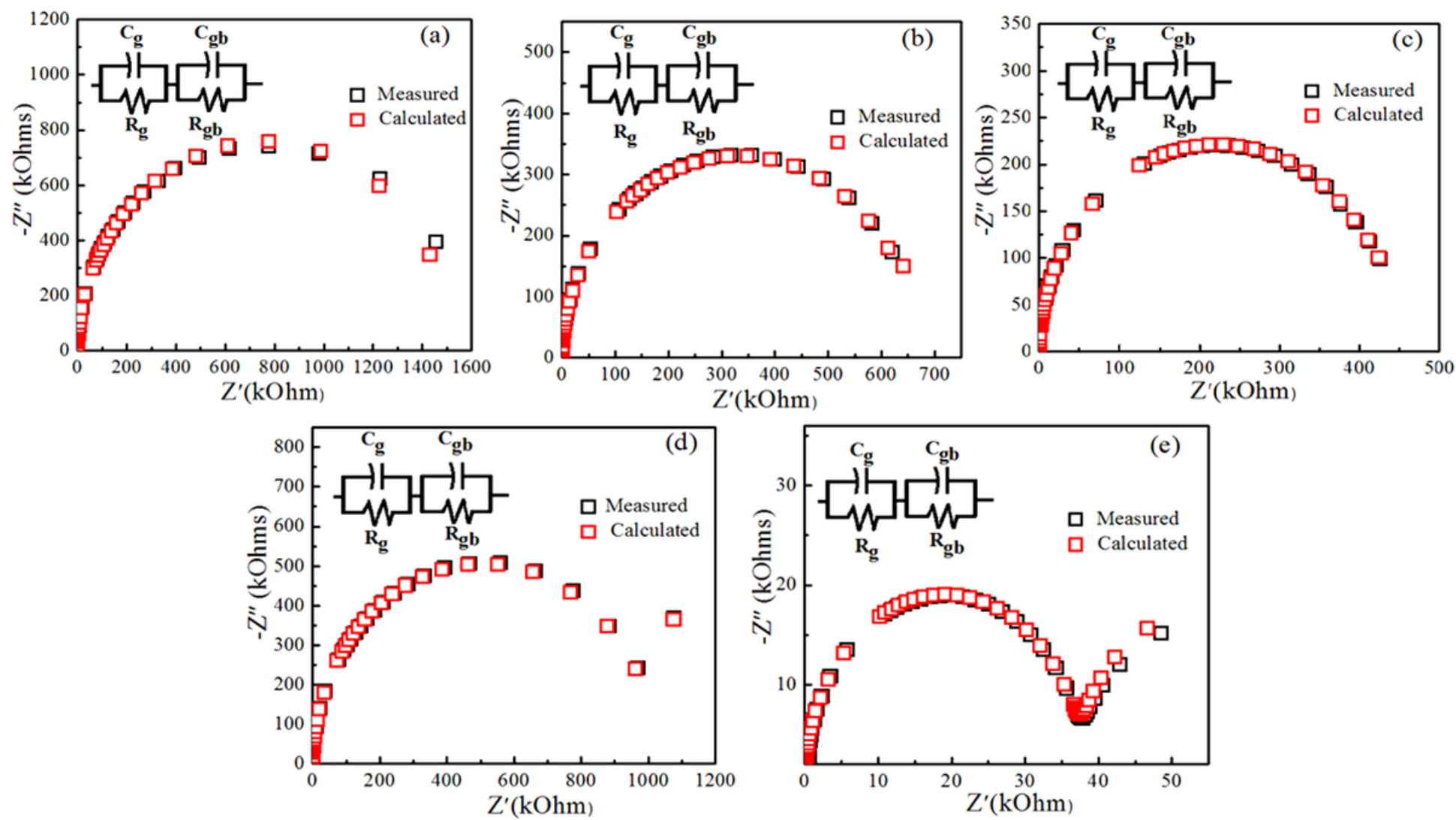

Figure 4

The Nyquist plots for the MZT films deposited at (a) (1:0) O2/Ar, (b) (3:1) O2/Ar, (c) (1:1) O2/Ar, (d) (1:3) O2/Ar and (e) (0:1) 02/Ar.
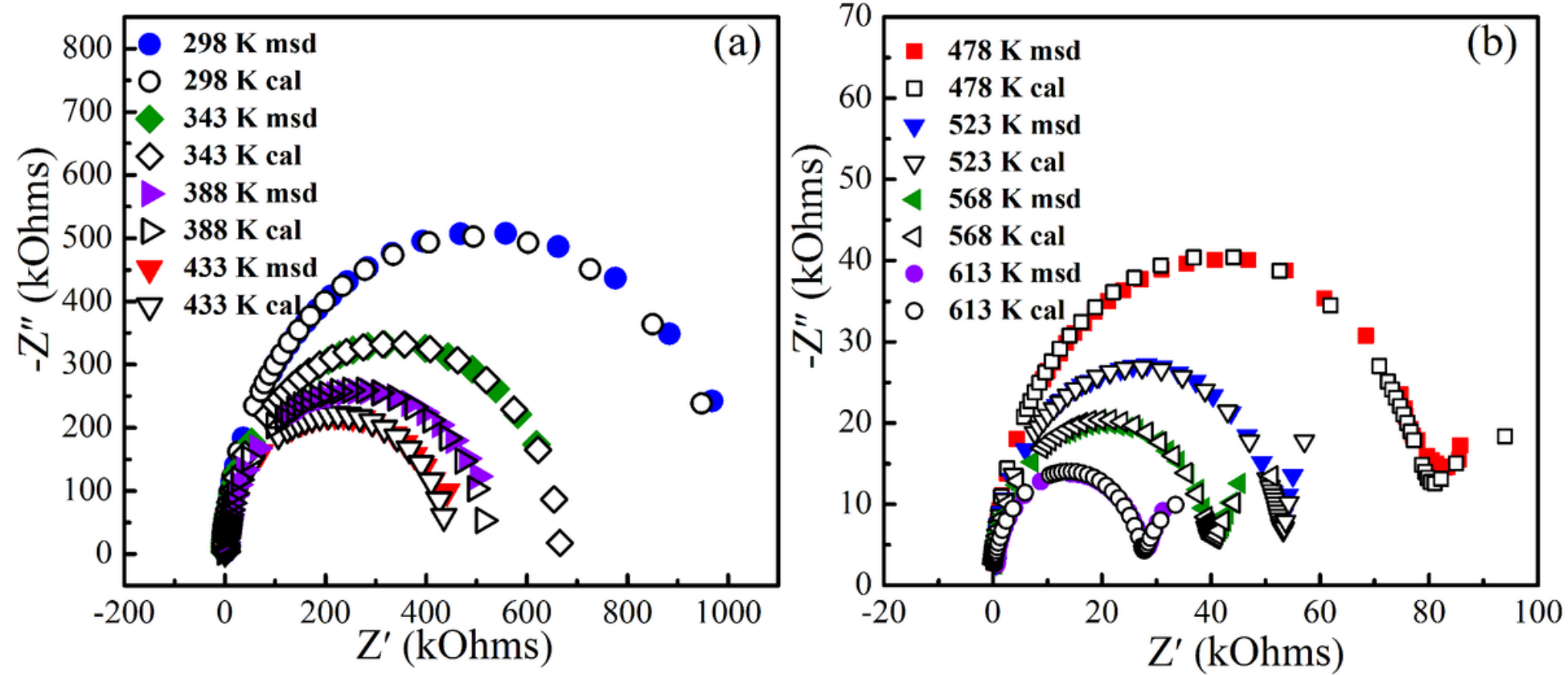

Figure 5 
The measured (msd) and calculated (cal) Nyquist plots for the MZT films deposited at (1:0) 02/Ar at different temperatures (a) $298 \mathrm{~K}-433 \mathrm{~K}$ and (b) $478 \mathrm{~K}-613 \mathrm{~K}$.
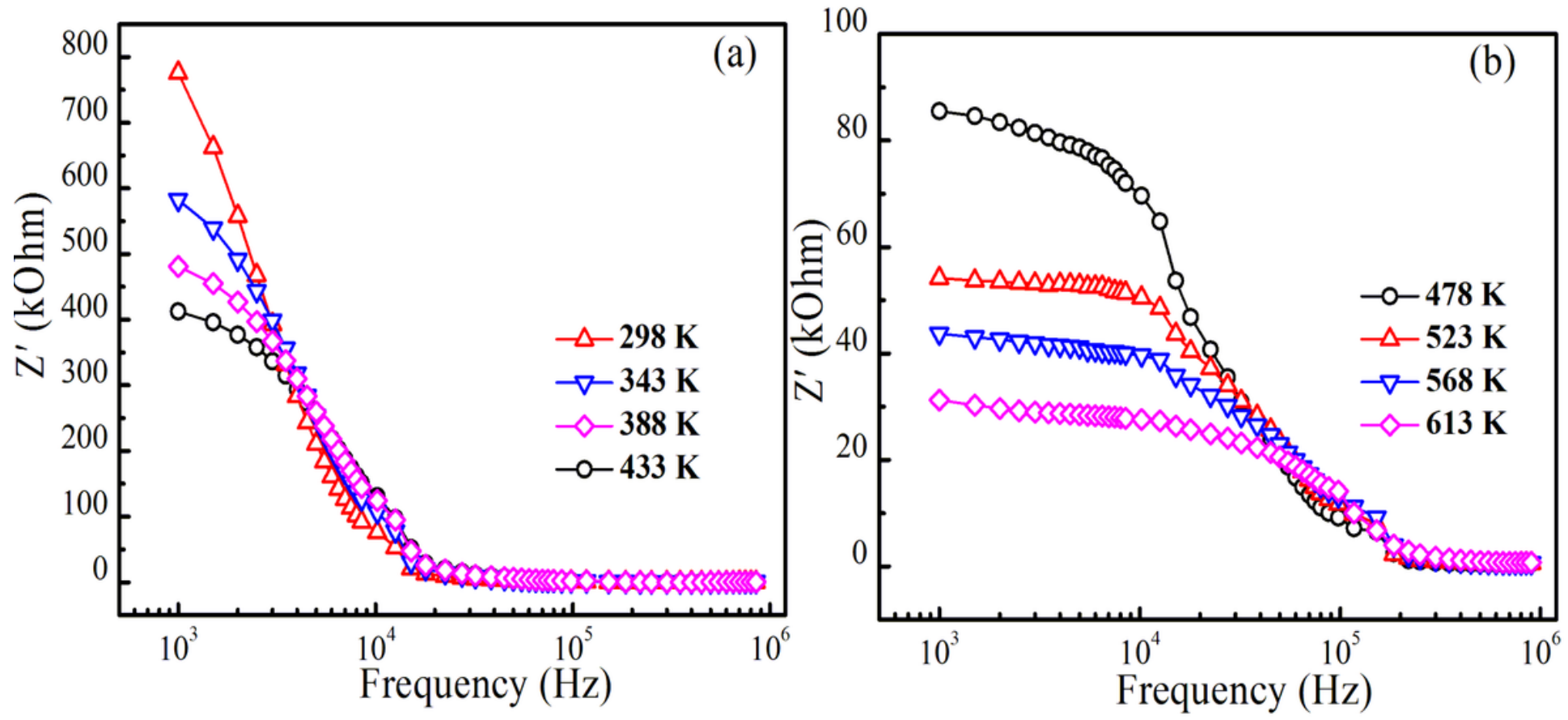

Figure 6

Variation of the real part of impedance ( $Z^{\prime}$ ) measured at different temperatures (a) $298 \mathrm{~K}-433 \mathrm{~K}$ and (b) $478 \mathrm{~K}-613 \mathrm{~K}$ for MZT thin film deposited under (1:0) 02/Ar ratio.
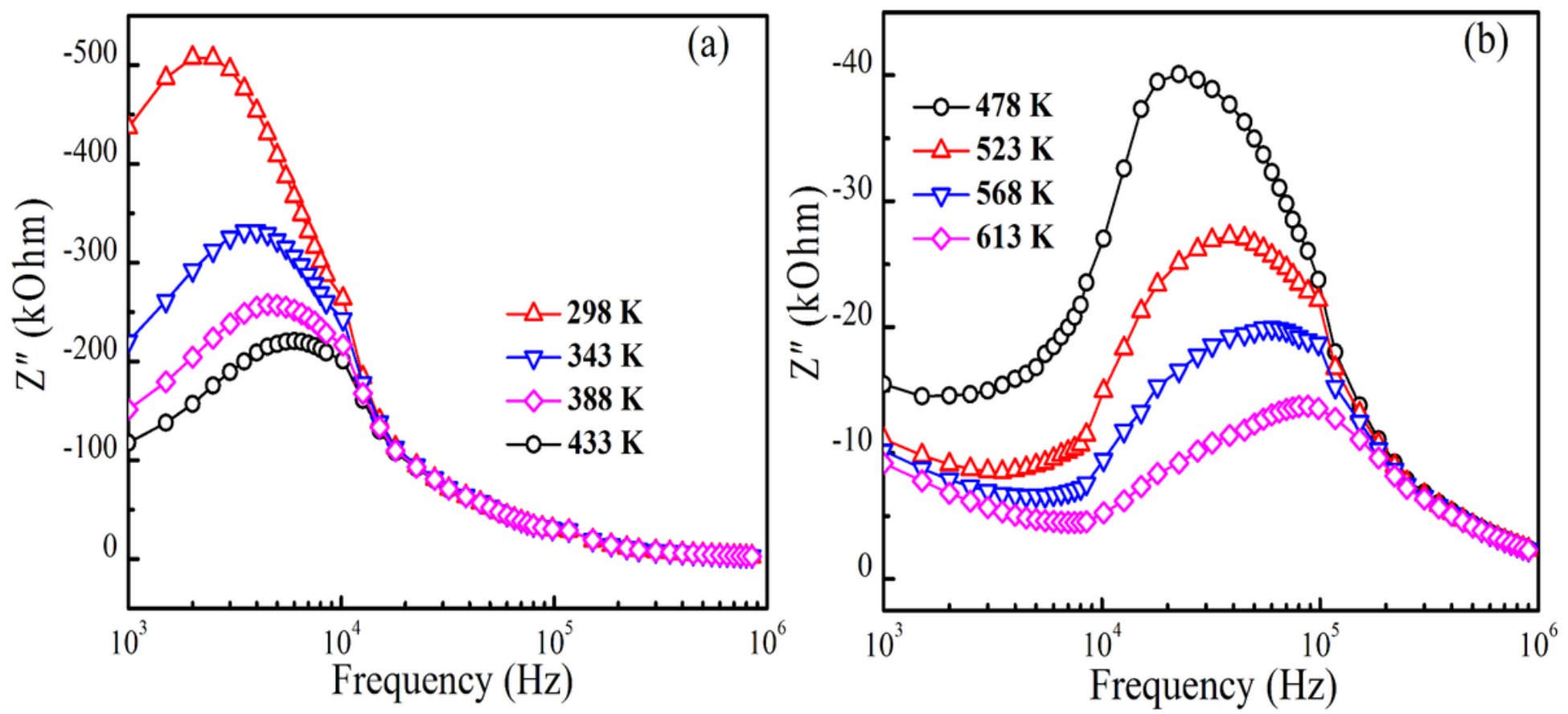

Figure 7 
Variation of the imaginary part of impedance (Z") measured at different temperatures (a) $298 \mathrm{~K}-433 \mathrm{~K}$ and (b) $478 \mathrm{~K}-613 \mathrm{~K}$ for MZT thin film deposited under (1:0) 02/Ar ratio. 